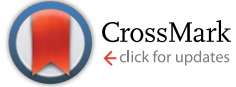

Cite this: RSC Adv., 2016, 6, 83520

Received 6th May 2016

Accepted 20th August 2016

DOI: 10.1039/c6ra11819d

www.rsc.org/advances

\section{Microwave-assisted synthesis of highly crystalline, multifunctional iron oxide nanocomposites for imaging applications $\uparrow$}

\author{
Marc J. Williams, ${ }^{b}$ Enrique Sánchez, ${ }^{a}$ Esther Rani Aluri, ${ }^{a}$ Fraser J. Douglas, ${ }^{c}$ \\ Donald A. MacLaren, ${ }^{C}$ Oonagh M. Collins, ${ }^{d}$ Edmund J. Cussen, ${ }^{d}$ James D. Budge, \\ Lara C. Sanders, ${ }^{e}$ Martin Michaelis, ${ }^{e}$ C. Mark Smales, ${ }^{e}$ Jindrich Cinatl, Jr, ${ }^{f}$ \\ Silvia Lorrio, ${ }^{\text {gh }}$ Dirk Krueger, ${ }^{9}$ Rafael T. M. de Rosales ${ }^{g}$ and Serena A. Corr ${ }^{\star a}$
}

\begin{abstract}
We report a reproducible single-step, microwave-assisted approach for the preparation of multifunctional magnetic nanocomposites comprising superparamagnetic iron oxide $\left(\mathrm{Fe}_{3} \mathrm{O}_{4}\right)$ cores, a polyelectrolyte stabilizer and an organic dye with no requirement for post-processing. The stabilisers poly(sodium 4styrenesulfonate) (PSSS) and sodium polyphosphate (SPP) have been thoroughly investigated and from analysis using electron microscopy, dynamic light scattering measurements, magnetic hysteresis and magnetic resonance (MR) imaging, we show that the higher degree of $\mathrm{Fe}_{3} \mathrm{O}_{4}$ nanoparticle crystallinity achieved with the PSSS stabiliser leads to enhanced magnetic behaviour and thus better contrast agent relaxivity compared to the less crystalline, poorly defined particles obtained when SPP is employed as a stabiliser. We also demonstrate the potential for obtaining a multifunctional magnetic-fluorescent nanocomposite using our microwave-assisted synthesis. In this manner, we demonstrate the intimate link between synthetic methodology (microwave heating with a polyelectrolyte stabilizer) and the resulting properties (particle size, shape, and magnetism) and how this underpins the functionality of the resulting nanocomposites as agents for biomedical imaging.
\end{abstract}

\section{Introduction}

The choice of synthetic approach employed for the preparation of nanoparticles is of crucial importance when designing materials for a specific function. Of growing recent interest has been the development of routes to nanoparticles which afford great control over particle shape and composition, vital in our efforts to realise an intimate understanding of their unique properties. One example is the field of magnetic nanoparticles,

${ }^{a}$ School of Chemistry, University of Glasgow, Glasgow G12 8QQ, UK. E-mail: serena. corr@glasgow.ac.uk; Tel: +44 (0)141 3302274

${ }^{b}$ School of Physical Sciences, University of Kent, Canterbury CT2 $7 N H$, UK

${ }^{c}$ School of Physics and Astronomy, University of Glasgow, Glasgow G12 8QQ, UK

${ }^{d}$ Department of Pure and Applied Chemistry, University of Strathclyde, Glasgow G1 $1 X L, U K$

${ }^{e}$ Centre for Molecular Processing and School of Biosciences, University of Kent, Canterbury CT2 7NJ, UK

Institut für Medizinische Virologie, Klinikum der Goethe-Universität, Paul EhrlichStrasse 40, 60596 Frankfurt am Main, Germany

${ }^{g}$ Division of Imaging Sciences and Biomedical Engineering, King's College London, St Thomas' Hospital, London, SE1 TEH, UK

${ }^{h}$ The British Heart Foundation Centre of Excellence, Cardiovascular Division, King's College London, London, UK

$\dagger$ Electronic supplementary information (ESI) available. See DOI: 10.1039/c6ra11819d a class of materials whose size-dependent magnetic properties opens up their potential applications for hyperthermic cancer therapy, site-specific drug delivery and contrast enhancement in magnetic resonance (MR) imaging. ${ }^{\mathbf{1 1 1}}$ Control over the magnetic properties is desirable in order to tailor the candidate nanoparticle for a specific biomedical application. ${ }^{12}$ Magnetic nanoparticles may be synthesised in a variety of ways, ${ }^{\mathbf{1 3 - 1 5}}$ including by co-precipitation, ${ }^{16,17}$ hydrothermal methods, ${ }^{18}$ and the decomposition of precursors at elevated temperatures. ${ }^{\mathbf{1 9 , 2 0}}$ Aqueous routes, such as co-precipitation, are advantageous in that the particles are prepared in biologically tolerated solvents, but often lead to polydisperse nanoparticles which may display some loss of particle crystallinity. ${ }^{21}$ Advances made in the high temperature decomposition of organometallic precursors have led to highly crystalline, monodisperse nanoparticles, with a great degree of control over particle size. ${ }^{22}$ These routes, where organic solvents are employed, generate hydrophobic nanoparticles, with additional work-up required to transfer the particles to aqueous environments for subsequent biomedical use. A synthetic approach which produces nanoparticles with high crystallinity without the need for surface post-processing to induce hydrophilicity is therefore highly desirable.

With these concerns in mind, we have employed microwaveassisted methods for the preparation of functionalised iron oxide nanoparticles, which are becoming increasingly attractive 
in materials chemistry. Microwave approaches to particle synthesis have led to dramatic decreases in reaction times and greater control over product formation. ${ }^{23-29}$ For example, the Niederberger group has developed microwave-assisted methods to prepare a range of nanoparticles of controlled sizes within minutes. ${ }^{30}$ Since the first reports of the microwave-promoted hydrothermal synthesis of sub-micron haematite powders, ${ }^{31}$ methods have been developed to prepare nanoparticles of uniform size distribution. Nanoparticles of haematite $\left(\alpha-\mathrm{Fe}_{2} \mathrm{O}_{3}\right)$ have been reported from the irradiation of hydrolysed iron salts, ${ }^{32}$ while more exotic $\alpha-\mathrm{Fe}_{2} \mathrm{O}_{3}$ morphologies (cubes, rings and spindles) have been realised by $\mathrm{Yu}$ and co-workers by tailoring the reaction conditions to provide thermodynamic control over particle growth. ${ }^{33,34}$ Superparamagnetic maghemite $\left(\gamma-\mathrm{Fe}_{2} \mathrm{O}_{3}\right)$ nanoparticles may be prepared through a microwavetreated co-precipitation reaction with a typical particle size of 10 nm obtained..$^{35}$ Increases in nanoparticle crystallinity have been observed upon aging under microwave conditions, with postprocessing using stearic acid resulting in stable organic ferrofluids. $^{36}$ Uptake in endothelial cells of superparamagnetic citrate-coated $\mathrm{Fe}_{2} \mathrm{O}_{3}$ nanoparticles prepared by microwaveassisted methods have also recently been reported. ${ }^{37}$ Variation of reactant concentration in the microemulsion synthesis of $\mathrm{Fe}_{3} \mathrm{O}_{4}$ under microwave irradiation has resulted in monodisperse composites of variable sizes. ${ }^{38}$ Reaction time for the polyol synthesis of cobalt ferrite nanoparticles has been decreased to just one hour by combining microwave heating, ${ }^{39}$ while a variety of $\mathrm{MFe}_{2} \mathrm{O}_{4}$ ferrites $(\mathrm{M}=\mathrm{Zn}, \mathrm{Ni}, \mathrm{Mn}, \mathrm{Co})$ have also been reported from microwave-hydrothermal methods. ${ }^{40}$

For their use as imaging agents, tailoring the surface chemistry of magnetic nanoparticles is essential. ${ }^{\text {22,41-44 }}$ For example, Liong et al. have reported the preparation of a multifunctional nanocomposite for imaging and targeted drug delivery where iron oxide nanoparticles are phase transferred from an organic to an aqueous solution before silica coating and co-condensation of a fluorescent moiety render them multifunctional. ${ }^{45}$ Recently, Liu et al. have reported the use of polyacrylic acid in the synthesis of $\mathrm{Fe}_{3} \mathrm{O}_{4}$ nanoparticles to achieve tuneable particle cluster sizes of between $100 \mathrm{~nm}$ and 400 $\mathrm{nm}$, which display good biocompatability. ${ }^{46}$ We have previously reported the use of polyelectrolytes for the in situ stabilisation of magnetic nanoparticles during a co-precipitation reaction, which has led to new developments in magnetic fluid preparation. ${ }^{4-49}$ Employing polyelectrolyte stabilisers in situ during nanoparticle nucleation and growth confers a high degree of stability induced by strong affinity of the anionic groups to the metal cations, with stable aqueous suspensions in the presence of a $0.5 \mathrm{~T}$ magnetic field obtained.

Here, we report the reproducible, repeatable preparation of bare $\mathrm{Fe}_{3} \mathrm{O}_{4}$ nanoparticles and the first use of microwave synthesis to obtain multi-coordinating polyelectrolytestabilised $\mathrm{Fe}_{3} \mathrm{O}_{4}$ nanoparticles and polyelectrolyte-stabilised magnetic fluids functionalised with a fluorescent dye according to Fig. 1. We are particularly interested in what effect, if any, the choice of polyelectrolyte stabiliser has on the resulting nanoparticle shape, size and crystallinity. The polyelectrolytes used were poly(sodium 4-styrenesulfonate) (PSSS), which has

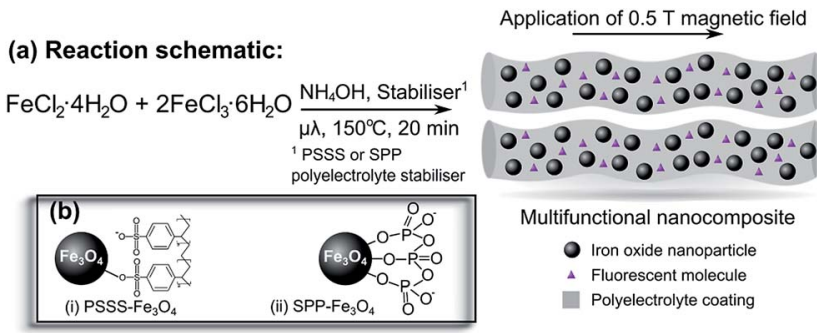

Fig. 1 (a) Schematic representation of the one-pot synthesis of the multifunctional nanocomposite material, using microwave irradiation. Application of an external 0.5 T magnetic field may induce linear assemblies. Legend shows iron oxide nanoparticles, a fluorescent molecule (in this case, Rhodamine B), and a polyelectrolyte coating which make up this nanocomposite. (b) Binding of (i) PSSS and (ii) SPP stabilisers to the iron oxide nanoparticle surface.

been employed previously as a stabiliser in a traditional coprecipitation reaction, ${ }^{\mathbf{4 8}}$ and sodium polyphosphate (SPP) which was employed as an in situ stabiliser for the first time, where the sulfonate and phosphate groups, respectively, bind to the iron ions in solution prior to particle precipitation. In this manner, the polyelectrolytes act as stabilisers preventing the further growth of the nanoparticles, while at the same time promoting colloidal stability of the particles in water.

\section{Results and discussion}

A modified co-precipitation technique has been employed, wherein a precursor solution of ferric and ferrous chlorides in the presence of polyelectrolyte solution was first prepared. The co-precipitation method involves several processes: nucleation, seed formation and growth. ${ }^{\mathbf{5 0 , 5 1}}$ Rapid particle nucleation follows the addition of ammonia base, after which the particle suspension is transferred to a microwave cavity and particle growth occurs under microwave irradiation at $150{ }^{\circ} \mathrm{C}$ for 20 min. All samples were washed until neutral. In the case of the bare particles, the sample was dried for further analysis. For the polyelectrolyte samples, the final, neutral fifth washings were highly stable colloidal suspensions, which have been characterised using dynamic light scattering (DLS), transmission electron microscopy (TEM), and MR imaging, and their cellular interactions were analysed. The remaining solids were dried and analysed using X-ray diffraction (XRD), X-ray absorption spectroscopy (XAS), SQUID magnetometry, thermogravimetric analysis (TGA) and IR.

XRD patterns collected on dried powders of each sample are shown in Fig. 2(a). For comparison, a diffraction pattern was also collected of magnetite nanoparticles prepared using the traditional co-precipitation route without any microwave treatment (red line). The patterns obtained for all samples may be indexed to the cubic spinel, magnetite $\left(\mathrm{Fe}_{3} \mathrm{O}_{4}\right)$. The broad peaks observed are typical for nanoparticles and the particle sizes, which may be obtained from the Scherrer equation, are included in Table 1. These are on the order of $10 \mathrm{~nm}$. Also shown in Fig. 2 are the patterns obtained for polyelectrolytestabilised samples, labelled $\mathrm{PSSS}-\mathrm{Fe}_{3} \mathrm{O}_{4}$ and $\mathrm{SPP}-\mathrm{Fe}_{3} \mathrm{O}_{4}$. Given 

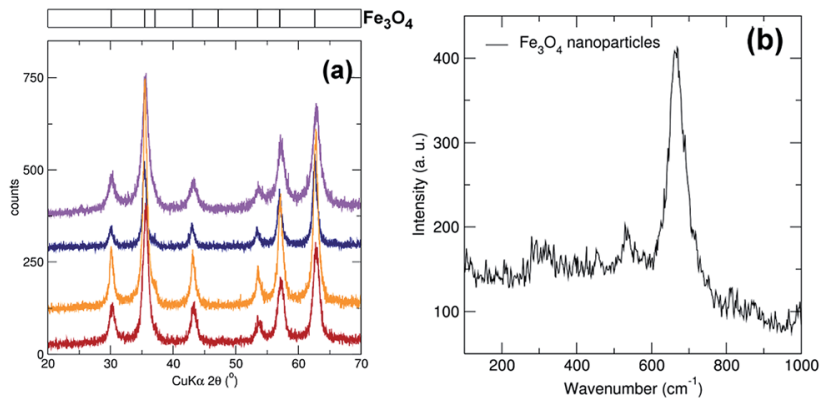

Fig. 2 (a) Powder XRD patterns for samples prepared using microwave-assisted methods: bare magnetite (orange), $\mathrm{PSSS}-\mathrm{Fe}_{3} \mathrm{O}_{4}$ (navy) and $\mathrm{SPP}-\mathrm{Fe}_{3} \mathrm{O}_{4}$ (purple). For comparison, a pattern of magnetite nanoparticles prepared using traditional co-precipitation synthesis is included (red) together with a reference ICSD pattern. (b) Raman spectrum of pure $\mathrm{Fe}_{3} \mathrm{O}_{4}$ nanoparticles prepared using microwaveassisted method. Peak at $664 \mathrm{~cm}^{-1}$ is assigned to $A_{1 \mathrm{~g}}$ mode of magnetite, with $E_{g}$ and $T_{2 g}$ modes centered at 301 and $527 \mathrm{~cm}^{-1}$ respectively. No peaks for haematite or maghemite were observed.

that the XRD patterns for magnetite and maghemite are similar, Raman spectroscopy measurements were performed. Using Raman spectroscopy, it is possible to assign characteristic peaks for magnetite (which contains both $\mathrm{Fe}^{3+}$ and $\mathrm{Fe}^{2+}$ ions) and the oxidised iron oxides maghemite $\left(\gamma-\mathrm{Fe}_{2} \mathrm{O}_{3}\right)$ and haematite $(\alpha-$ $\mathrm{Fe}_{2} \mathrm{O}_{3}$ ). Fig. 2(b) shows the resulting Raman spectrum for the pure uncoated nanoparticles, displaying a strong peak at 664 $\mathrm{cm}^{-1}$ which can be attributed to the $\mathrm{A}_{1 \mathrm{~g}}$ mode of magnetite. Also visible are the $E_{g}$ and $T_{2 g}$ modes, centered at 301 and $527 \mathrm{~cm}^{-1}$ respectively. All peaks observed are in excellent agreement with previous assignments for magnetite in the literature. ${ }^{4,52,53}$ There are no peaks for haematite or maghemite observed.

The comparatively broader peak shapes for the $\mathrm{Fe}_{3} \mathrm{O}_{4}-\mathrm{SPP}$ sample are reflected in the decreased particle size values obtained from the Scherrer equation for these particles $(10.9 \mathrm{~nm}$ for SPP-coated particles, $11.2 \mathrm{~nm}$ for uncoated nanoparticles). HRTEM images for pure $\mathrm{Fe}_{3} \mathrm{O}_{4}$ samples reveal single-crystal nanoparticles (see Fig. 3). The $\mathrm{Fe}_{3} \mathrm{O}_{4}$ particles are aggregated, with a typical particle size of $12 \pm 2 \mathrm{~nm}$ (measured for $N=100$ particles). Analysis of lattice spacing and SAED patterns, shown in Fig. 3(d), confirm the nanoparticles to be magnetite $\left(\mathrm{Fe}_{3} \mathrm{O}_{4}\right.$, JCPDS index card number 19-629). It is clear from these measurements that the microwave iron oxide sample contains both $\mathrm{Fe}^{2+}$ and $\mathrm{Fe}^{3+}$ ions, in good agreement with the Rietveld profile analysis of this sample to $\mathrm{Fe}_{3} \mathrm{O}_{4}$.

Interestingly, the nanoparticle shape, size and aggregate nature are significantly affected by the polyelectrolyte stabilisers

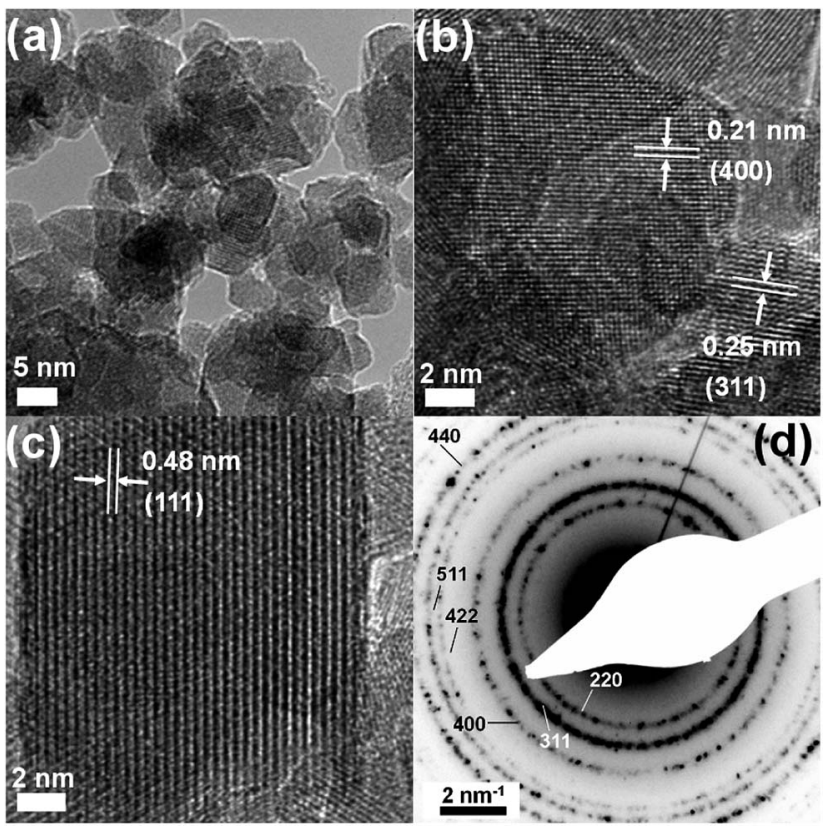

Fig. 3 (a) HRTEM images of bare $\mathrm{Fe}_{3} \mathrm{O}_{4}$ nanoparticles prepared by microwave routes reveal aggregation of discrete nanoparticles. Each individual particle is highly crystalline, with lattice fringes clearly visible. ( $b$ and $c$ ) The interplanar spacings are indexed to the corresponding magnetite $(h k l)$ reflection. (d) SAED pattern from an agglomerate of particles, with the pattern indexed to magnetite.

employed under otherwise identical reaction conditions. Electron microscopy images of the polyelectrolyte-stabilised samples are shown in Fig. 4, where the presence of the PSSSpolyelectrolyte is evidenced by the core-shell appearance of the nanocomposite (Fig. 4(a)). The presence of polyelectrolyte on the PSSS- and SPP- $\mathrm{Fe}_{3} \mathrm{O}_{4}$ nanoparticle surface has also been confirmed using IR spectroscopy (see ESI Fig. S1†). Both samples give an $\mathrm{Fe}-\mathrm{O}$ stretch at $\sim 530 \mathrm{~cm}^{-1}$ and a broad stretch at $3400 \mathrm{~cm}^{-1}$ for physically adsorbed water on the particle surface. In the case of PSSS- $\mathrm{Fe}_{3} \mathrm{O}_{4}$, an $\mathrm{Fe}-\mathrm{O}-\mathrm{S}$ stretch is noted at $669 \mathrm{~cm}^{-1}$, which indicates that the mode of binding is through the sulfonate group to the surface iron atoms of the nanoparticles. There are also stretches noted for the sulfonate groups at $775,830,1115,1160$ and $1405 \mathrm{~cm}^{-1}$. In the case of the SPP$\mathrm{Fe}_{3} \mathrm{O}_{4}$ sample, an Fe-O-P stretch is observed at $992 \mathrm{~cm}^{-1}$, indicating that the mode of binding is via the phosphate groups to the surface iron atoms. Stretches relating to the phosphate groups are also observed at 869 and $1255 \mathrm{~cm}^{-1}$. TGA plots for

Table 1 Average particle sizes calculated from the Scherrer equation using XRD patterns collected, TEM $(N=100$ particles, size given in nm with standard deviation) and DLS where $Z$-ave is the hydrodynamic radius and PDI the polydispersity index

\begin{tabular}{llcll}
\hline Sample & $\begin{array}{l}\text { XRD (size } \\
\text { nm) }\end{array}$ & TEM (size nm) & DLS Z-ave (PDI) & $\begin{array}{l}\text { Zeta potential } \\
(\mathrm{mV})\end{array}$ \\
\hline $\mathrm{Fe}_{3} \mathrm{O}_{4}$ & 11.2 & $12 \pm 2$ & N/A (N/A) & N/A \\
$\mathrm{Fe}_{3} \mathrm{O}_{4}-\mathrm{PSSS}$ & 16.1 & $13.4 \pm 1.5$ & $94.74(0.097)$ & -41.5 \\
$\mathrm{Fe}_{3} \mathrm{O}_{4}-\mathrm{SPP}$ & 10.9 & $10.1 \pm 1.5$ & $104.93(0.158)$
\end{tabular}

${ }^{a}$ No measurements were carried out on pure $\mathrm{Fe}_{3} \mathrm{O}_{4}$ nanoparticles prepared using microwave methods as no stable suspension resulted. 


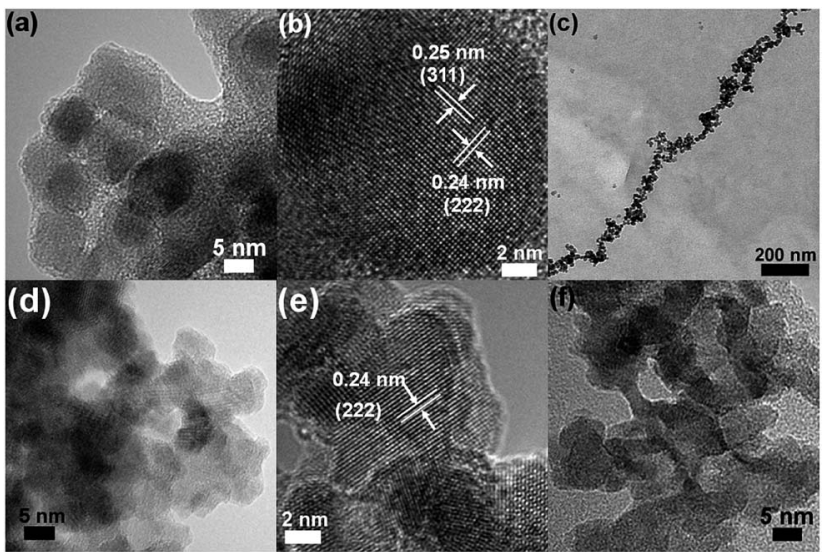

Fig. 4 HRTEM images of ( $a$ and b) PSSS- and ( $d$ and e) SPP- $\mathrm{Fe}_{3} \mathrm{O}_{4}$ nanoparticles. The major difference here is the irregular particle shape of the SPP $-\mathrm{Fe}_{3} \mathrm{O}_{4}$ (f) compared to PSSS $-\mathrm{Fe}_{3} \mathrm{O}_{4}$ which has a core-shell appearance. The formation of regular, linear assemblies is noted for the PSSS $-\mathrm{Fe}_{3} \mathrm{O}_{4}$ samples (c) upon application of a $0.5 \mathrm{~T}$ magnetic field.

bare magnetite, PSSS- and SPP- $\mathrm{Fe}_{3} \mathrm{O}_{4}$ nanoparticles are shown in ESI Fig. S2a. $\uparrow$ The mass loss for pure magnetite is low at 3.4\% and likely represents the loss of strongly adsorbed water and dehydration of surface hydroxyl groups. The mass losses are greater for the PSSS- and SPP- $\mathrm{Fe}_{3} \mathrm{O}_{4}$ samples, at 9.3\% and 7.8\% respectively, due to the removal of the polyelectrolyte surfactant at increasing temperatures. For both polyelectrolytes, the particles appear aggregated in the electron microscopy images (Fig. 4), with higher magnification images clearly showing each agglomerated region consisting of numerous discrete nanoparticles, which are clustered together. The shape of pure $\mathrm{Fe}_{3} \mathrm{O}_{4}$ and PSSS- $\mathrm{Fe}_{3} \mathrm{O}_{4}$ nanoparticles appear better defined than the $\mathrm{SPP}-\mathrm{Fe}_{3} \mathrm{O}_{4}$ sample, whose particles appear smaller on average and irregular in shape (Fig. 4(f)). A high degree of crystallinity of these polyelectrolyte-stabilised nanoparticles is observed, where lattice spacings consistent with magnetite are identified. SAED patterns are in excellent agreement with these observations (shown in ESI Fig. S3†).

In order to probe the behaviour of these polyelectrolyte nanocomposites in the presence of a magnetic field, samples were dried in a $0.5 \mathrm{~T}$ magnetic field and analysed using microscopy. In the case of the PSSS-stabilised nanoparticles, linear assemblies are observed (Fig. 4(c)); reminiscent of previous reports for samples prepared by co-precipitation alone. $^{48}$ Currently, we are focussing attention on understanding how the nature of the polyelectrolyte and the chain length affect the formation of these linear assemblies and the resulting implications on imaging behaviour of nanoparticulate contrast agents.

The aggregation of these stabilised nanoparticles has been investigated further by measuring the average hydrodynamic radii at $298 \mathrm{~K}$ using DLS (ESI Fig. S2(b)†). For both samples and for a range of reproduced reactions, this average is found to be close to $100 \mathrm{~nm}$. The polydispersity of the $\mathrm{SPP}-\mathrm{Fe}_{3} \mathrm{O}_{4}$ sample is greater than that for the PSSS- $\mathrm{Fe}_{3} \mathrm{O}_{4}$ sample, which is evidenced by the broader peak shape and the slightly higher polydispersity index (PDI) (0.158 for SPP- $\mathrm{Fe}_{3} \mathrm{O}_{4}$ and 0.097 for $\mathrm{PSSS}-\mathrm{Fe}_{3} \mathrm{O}_{4}$ ). The low values obtained for the PDI values $(<0.2)$ indicate a unimodal distribution of monodisperse clusters for both samples. Upon exposure to a $0.5 \mathrm{~T}$ magnetic field these values do not change, confirming the excellent water stability these polyelectrolyte stabilisers confer on the $\mathrm{Fe}_{3} \mathrm{O}_{4}$ nanoparticles prepared using microwave methods. Table 1 summarises the particle sizes as calculated from Scherrer broadening (XRD), average particle size (TEM), hydrodynamic radius and zeta potential (DLS). The observed zeta potentials are below $-30 \mathrm{mV}$ for both samples, which confirms the negative surface charge we postulate in Fig. 1 and reaffirms the excellent water stability of these suspensions, which was the case over a six month period as confirmed by DLS analysis. ${ }^{54}$

Magnetization curves were measured at $300 \mathrm{~K}$ and $10 \mathrm{~K}$ in a magnetic field of up to $2 \times 10^{4} \mathrm{G}$ and are shown in Fig. 5 . There is negligible coercivity and remanence noted at $300 \mathrm{~K}$, indicative of superparamagnetic, single-domain iron oxide particles. The magnetization is unsaturated up to $2 \mathrm{~T}$, even at 10 K. Uncoated magnetite prepared using our microwave-assisted method gives a saturation magnetisation of $67.6 \mathrm{emu}^{-1}$ at $300 \mathrm{~K}$. While this is lower than the theoretical value for bulk magnetite of $98 \mathrm{emu} \mathrm{g}^{-1}$ (most likely due to spin disorder on the particle surface ${ }^{55}$ ), this value is higher than previously reported saturation magnetisation values for aqueous routes to iron oxide nanoparticles (40-50 emu $\left.\mathrm{g}^{-1}\right) .{ }^{56,57}$ By employing polyelectrolytes as stabilisers we have found that primary particle sizes and morphologies change and this, in turn, has a marked effect on the resulting magnetic properties. The SPP-stabilised particles are smaller in size, with ill-defined shape, and this is reflected in the reduced $M_{\mathrm{s}}$ value of $53.9 \mathrm{emu} \mathrm{g}^{-1}$ at $300 \mathrm{~K}$. The PSSS-stabilised samples, on the other hand, have an $M_{\mathrm{s}}$ value of $77.1 \mathrm{emu}^{-1}$ at $300 \mathrm{~K}$ and appear highly crystalline in HRTEM. Interestingly, the magnetisation value here is significantly higher than $M_{\mathrm{s}}$ values previously obtained from NMRD data for PSSS-stabilised $\mathrm{Fe}_{3} \mathrm{O}_{4}\left(30-50\right.$ emu $\left.\mathrm{g}^{-1}\right)$ prepared without the additional microwave synthesis step. ${ }^{58}$

The saturation magnetisation value is greatly affected by the crystallinity of the sample. For high temperature decomposition routes using organic surfactants, for example, the highly crystalline and uniform nature of the particles is manifested in similarly higher $M_{\mathrm{s}}$ values $\left(\sim 80 \mathrm{emu} \mathrm{g}^{-1}\right) .{ }^{59}$ For biological use, organic-surfactant coated particles require further postprocessing to transfer into aqueous solutions to obtain stable
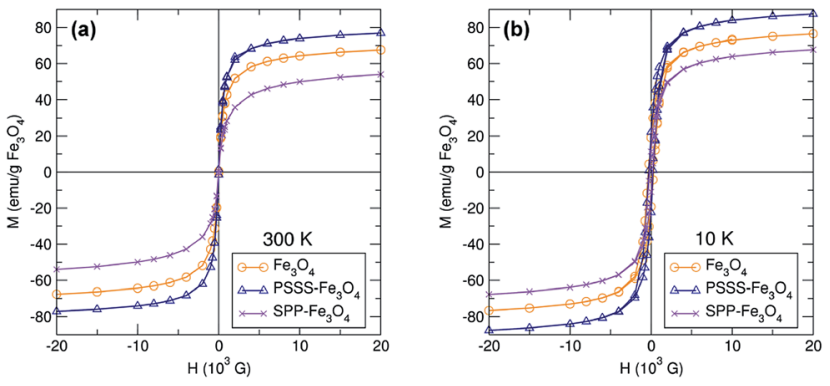

Fig. 5 Magnetic hysteresis loops of pure $\mathrm{Fe}_{3} \mathrm{O}_{4}, \mathrm{PSSS}-\mathrm{Fe}_{3} \mathrm{O}_{4}$ and $\mathrm{SPP}-\mathrm{Fe}_{3} \mathrm{O}_{4}$ at (a) $300 \mathrm{~K}$ and (b) $10 \mathrm{~K}$. Data are shown per gram of $\mathrm{Fe}_{3} \mathrm{O}_{4}$ which was determined from TGA results. 
suspensions. ${ }^{26,60}$ The microwave-assisted synthesis reported here achieves both properties in a single step: excellent magnetic properties combined with long-term aqueous stability. From these data, we have shown the combination of the PSSS stabiliser and microwave irradiation results in a waterstable crystalline material, without compromising the magnetic properties.

To evaluate the MR efficacy of the PSSS- $\mathrm{Fe}_{3} \mathrm{O}_{4}$ and SPP$\mathrm{Fe}_{3} \mathrm{O}_{4}$ samples, $T_{1}, T_{2}$ and $T_{2}^{*}$-weighted images were collected at varying Fe concentrations using a $3 \mathrm{~T}$ clinical MRI scanner. Relaxivity values are reported in Table 2 . Increasing $\mathrm{Fe}$ concentrations $\left(\sim 0-2 \mathrm{mM}\right.$ in $\left.\mathrm{H}_{2} \mathrm{O}\right)$ were imaged and are displayed in Fig. 6. Higher relaxation rates are noted upon increasing $\mathrm{Fe}$ concentration, because PSSS- $\mathrm{Fe}_{3} \mathrm{O}_{4}$ and SPP$\mathrm{Fe}_{3} \mathrm{O}_{4}$ shorten the $T_{2}$ relaxation time, which reduces the signal intensity, i.e. negative contrast. Interestingly, the contrast displayed by the PSSS- $\mathrm{Fe}_{3} \mathrm{O}_{4}$ sample is greater than that of the $\mathrm{SPP}-\mathrm{Fe}_{3} \mathrm{O}_{4}$ particles. The increased crystallinity of these particles and their enhanced magnetic properties are the major factors for this behaviour. Since it is the magnetic moments of the particles interacting with the water protons that result in image contrast, the crystalline nature of the particles is vital in determining how efficiently this may occur. In the case of the SPP-stabilised nanoparticles, the irregular shape and decrease in saturation magnetization point to greater disorder of the surface spins in these particles which will play a role in decreasing the imaging efficacy. This is in good agreement with an extensive study reported by Vuong et al., who have proposed a method for predicting $T_{2}$ relaxation based on the nanocrystal size and magnetization values. ${ }^{\mathbf{6 1}}$ For our PSSS- $\mathrm{Fe}_{3} \mathrm{O}_{4}$ particles, the excellent magnetic properties and the crystalline nature of the primary particle indicate the promising potential for these contrast agents for MR imaging. MR contrast properties for several other reports of functionalised iron oxide nanoparticles are also included in Table 2..$^{4,62,63}$

Enhanced MR contrast has been previously noted for linear assemblies of iron oxide nanoparticles. ${ }^{48,58,64}$ In the current case, we observe relaxivities on the order of commercially available contrast agents and nanoparticle suspensions prepared by high temperature decomposition routes, with the added advantage here of no additional work-up required to transfer to aqueous conditions. ${ }^{65-67}$ Recently, Zboril and co-workers reported extraordinarily high relaxivities of $735 \mathrm{mM} \mathrm{s}^{-1}$ for iron oxide nanoparticles with a $1 \mathrm{~nm}$ terephthalic acid coating, postulating that effective spin-transfer to surrounding water protons is mediated via $\pi$-conjugation pathways through the organic
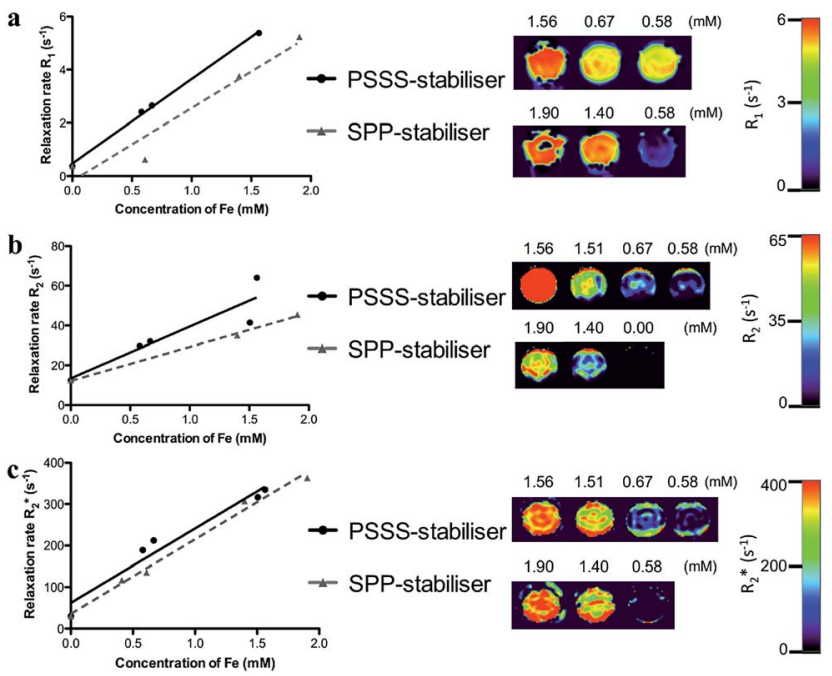

Fig. 6 Relaxivities of the PSSS (straight line) and SPP (dashed line) nanocomposites measured at $3 \mathrm{~T}$ and $20{ }^{\circ} \mathrm{C}$. Scatter plots show correlations between measured $R_{1}(\mathrm{a}), R_{2}(\mathrm{~b})$, and $R_{2}^{*}$ (c) values of the nanocomposites and iron concentrations measured using ICP-MS. The relaxation rates $\left(R_{1}, R_{2}\right.$ and $\left.R_{2}^{*}\right)$ were determined at $3 T$ using $T_{1}, T_{2}$ and $T_{2}^{*}$ mapping sequences, respectively, and aqueous solutions between 0 and $2 \mathrm{mM}$ of the contrast agents. Pearson's correlation coefficient values ranged from 0.92 to 0.99 . Phantom MRI images of the formulations show $R_{1}, R_{2}$ and $R_{2}^{*}$ maps in colour scale. $R_{1}, R_{2}$ and $R_{2}^{*}$ values increase with increasing concentrations of contrast agents (highest concentration on the left).

surfactant. ${ }^{68}$ It is enticing to consider the combined use of active spin-transfer surfactants with microwave processing to further optimise relaxivity behaviour.

The effect of stabiliser on cell toxicity was examined using cell viability studies on suspensions of the polyelectrolytestabilised particles co-incubated at increasing concentrations (0.001-1000 $\left.\mu \mathrm{g} \mathrm{L}^{-1}\right)$ with a range of cell lines and these results are depicted in Fig. 7. Regardless of the stabiliser employed, all nanoparticle suspensions tested were found to be non-toxic to a variety of mammalian cell lines, demonstrating the non-toxic robustness of these materials. Iron concentration ranges were similar to previous reports. ${ }^{69}$ This is determined by the fact they did not affect the viability of UKF-NB-3 neuroblastoma cells, primary human retinal pigment epithelial (RPE) cells, or primary human foreskin fibroblasts (HFF) even in concentrations up to $1 \mathrm{mg}$ of iron per L.

To demonstrate uptake into mammalian cells, fluorescentlylabelled samples were prepared by the addition of Rhodamine $\mathrm{B}$

Table 2 Samples and corresponding relaxation properties in $\mathrm{H}_{2} \mathrm{O}$ at $3 \mathrm{~T}$

\begin{tabular}{llllr}
\hline Sample & Field & $r_{1}\left(\mathrm{mM}^{-1} \mathrm{~s}^{-1}\right)$ & $r_{2}\left(\mathrm{mM}^{-1} \mathrm{~s}^{-1}\right)$ & $r_{2}^{*}\left(\mathrm{mM}^{-1} \mathrm{~s}^{-1}\right)$ \\
\hline $\mathrm{Fe}_{3} \mathrm{O}_{4}$-PSSS & $3 \mathrm{~T}$ & $3.18 \pm 0.10$ & $26.02 \pm 6.54$ & $179.00 \pm 22.75$ \\
$\mathrm{Fe}_{3} \mathrm{O}_{4}$-SPP & $3 \mathrm{~T}$ & $2.74 \pm 0.51$ & $17.04 \pm 0.91$ & $179.31 \pm 10.66$ \\
$\mathrm{Fe}_{3} \mathrm{O}_{4}$-PSSS (ref. 48) & $r_{2} / r_{1}$ \\
$\mathrm{Fe}_{3} \mathrm{O}_{4}$-PEG-BP (ref. 62) & $1.5 \mathrm{~T}$ & 7.2 & 89.4 & - \\
$\mathrm{Fe}_{3} \mathrm{O}_{4}$-PEG (ref. 63) & $3 \mathrm{~T}$ & 9.5 & 28.2 & - \\
\end{tabular}

${ }^{a}$ Note these measurements performed in $1.5 \mathrm{~T}$ field. 

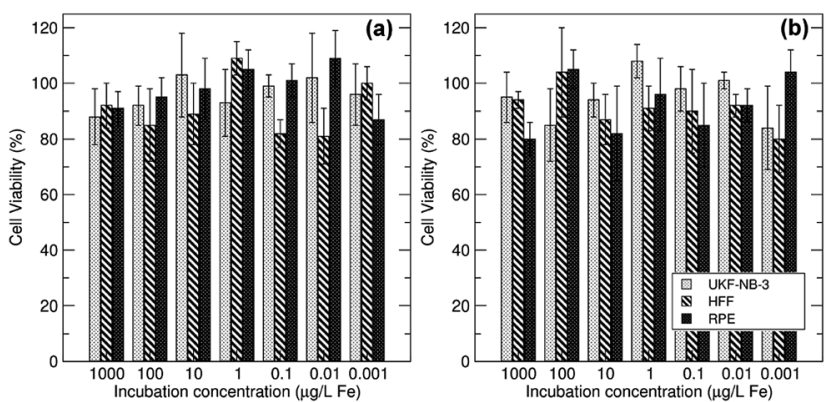

Fig. 7 Cytotoxicity profiles of (a) PSSS $-\mathrm{Fe}_{3} \mathrm{O}_{4}$ and (b) $\mathrm{SPP}-\mathrm{Fe}_{3} \mathrm{O}_{4}$ in three different cell lines of UKF-NB-3 neuroblastoma cells, primary human retinal pigment epithelial (RPE) cells and primary human foreskin fibroblasts (HFF) in concentrations up to $1 \mathrm{mg}$ iron per $\mathrm{L}$.

to the PSSS polyelectrolyte solution before particle precipitation, where association is driven by the electrostatic interactions between the dye and the polyelectrolyte. The fluorescent nature of the nanocomposite was confirmed using fluorescence spectroscopy $\left(\lambda_{\mathrm{ex}}=545 \mathrm{~nm}\right)$ and an enhanced aggregation of the composite is noted in DLS, where electrostatic interactions drive the formation of larger cluster sizes and this is reflected by the larger $Z$-ave (108.2 nm; PDI 0.169) (see ESI Fig. S4†). The sample spent several days under a $0.5 \mathrm{~T}$ magnetic field before DLS measurement to remove any larger aggregates and to ensure a stable suspension remained. Removal of any excess dye was confirmed by continuous washing of the sample and evaluation using fluorescence spectroscopy before redispersion into water and also by dialysis experiments of the resulting nanocomposite (see ESI Fig. S5†). Fig. 8 shows the resulting nanoparticle uptake by UKF-NB-3 neuroblastoma cells, which can be clearly located throughout the cytoplasm. Of importance here is that this internalisation process had no effect on viability as described above. Complementary $Z$-scan images confirm the location of the functionalised nanoparticles
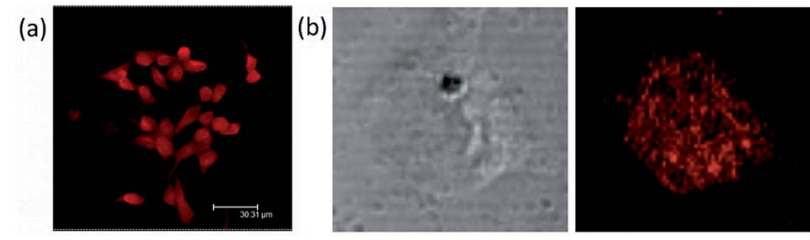

(c)
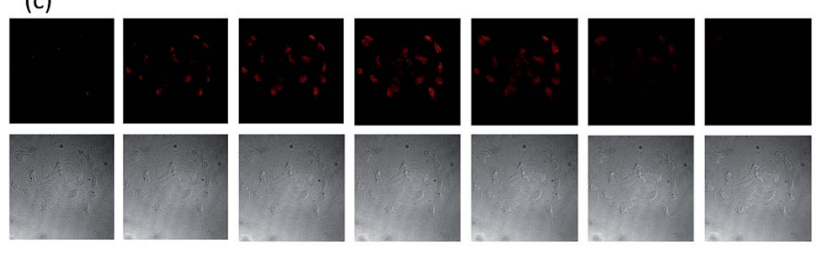

TOP

BOTTOM

Fig. 8 Immunofluorescence confocal microscopy imaging of UKFNB-3 neuroblastoma cells treated with nanoparticles for $24 \mathrm{~h}$. In all cells, the nanoparticle suspension was internalised (a) and particles appear punctated (b). Internalisation is confirmed when viewing slices through the cell (c). throughout the cell cytoplasm (Fig. 8(c)), rather than on the cell surface.

\section{Conclusions}

In conclusion, we have demonstrated a reproducible and reliable single step route to multifunctional magnetic nanocomposite materials, using a microwave-assisted synthesis, in order to provide stable magnetic fluids for use as MR contrast agents. Here, the underpinning structure-property relationship in these materials is highlighted by the synthetic approach taken and the resulting outcome this has on the functional properties of the nanocomposites. The choice of stabilizer polysulfate versus polyphosphate - has a substantial effect on the magnetic properties, which translates to their ability to enhance the relaxation mechanism of surrounding water protons in MR imaging. Whilst not the highest relaxivities reported for iron oxide nanocomposites, the comprehensive analysis presented here using a full range of characterisation techniques demonstrates PSSS as an excellent stabiliser for the preparation of multifunctional magnetic nanocomposite materials and our microwave-assisted synthetic approach can be applied to a full range of ferrite-based nanoparticles and polyelectrolyte-stabilised systems. Previous reports have shown that effective contrast agents can be obtained using PSSS as a stabiliser for iron oxide nanoparticles without any microwave treatment. ${ }^{48,58}$ In the case of the nanocomposites prepared without microwave heating, the hydrodynamic radius and polydispersity index is greater (136 $\mathrm{nm}$ and 0.21 , respectively). Most interesting though is that the saturation magnetisation (obtained from NMR dispersion measurements) is consistently lower for samples prepared without the application of microwave heating (30-50 $\left.\mathrm{emu}^{-1}\right)$. This has a resulting implication on the contrast agent efficacy (values of $r_{1}$ and $r_{2}$ obtained are of the same order for both samples, but for the sample prepared without microwave treatment, the relaxation properties were measured only at $1.5 \mathrm{~T}$ ). Therefore, the addition of this microwave heating step in the case of the PSSS stabiliser positively affects the subsequent properties and functionality of the nanocomposite. The direct link between particle crystallinity and the resulting magnetic behaviour and the governing effect this has on MR imaging capability is particularly interesting. We show that these nanocomposites are non-toxic to a range of mammalian cells, where their uptake can be confocally imaged. The ease of this approach allows for the preparation of extremely stable magnetic fluids for combined MR contrast efficacy and optical imaging and paves the way for a synthetic methodology which allows for greater control over final functionality.

\section{Experimental}

\subsection{Materials}

All materials were obtained from Sigma Aldrich. Millipore water was deoxygenated by boiling and then cooling under nitrogen gas. A CEM Discover SP system was used for microwave heating. FTIR spectra (400-2000 $\left.\mathrm{cm}^{-1}\right)$ were recorded using a Shimadzu 
IR Affinity-1 spectrophotometer. X-ray diffraction was performed on a Bruker D8 X-ray diffractometer and powder patterns were analysed using Rietveld refinement as embodied in the Fullprof suite. Thermogravimetric analysis was obtained with a Netzsch STA 409 PC Luxx TGA machine. All samples were heated in air to $700{ }^{\circ} \mathrm{C}$. Dynamic light scattering measurements were performed using a Malvern Zetasizer nano-ZS. Transmission electron microscopy (TEM) images were taken on a JEOL JEM (200-FX) operating at $120 \mathrm{kV}$. Samples were prepared on a formvar coated copper grid. Some grids were dried over a $0.5 \mathrm{~T}$ magnet. High resolution TEM and selected area electron diffraction (SAED) were performed on an FEI Tecnai TF20 instrument fitted with a field emission gun, operated at $200 \mathrm{keV}$. TEM samples were prepared by dispersing the sample in deionised water and dropping the solution onto an amorphous holey carbon coated grid. TEM data were obtained and processed using either Digital Micrograph or IMAGEJ 1.41 software.

\subsection{Preparation of magnetic nanocomposites}

$\mathrm{FeCl}_{3} \cdot 6 \mathrm{H}_{2} \mathrm{O}(2.70 \mathrm{~g} ; 10 \mathrm{mmol})$ and $\mathrm{FeCl}_{2} \cdot 4 \mathrm{H}_{2} \mathrm{O}(0.99 \mathrm{~g} ; 5 \mathrm{mmol})$ were dissolved in $10 \mathrm{~mL}$ of deoxygenated water. Polyelectrolyte stabiliser ( $0.2 \mathrm{~g}$ of either PSSS or SPP) was dissolved in the iron solution. The solution was heated to $80{ }^{\circ} \mathrm{C}$. Ammonia solution $(10 \mathrm{~mL} ; 28-30 \%)$ was injected at a rate of approximately $2.5 \mathrm{~mL}$ $\mathrm{s}^{-1}$ and the solution was stirred for 20 minutes before transferring to the microwave cavity to be heated at $150{ }^{\circ} \mathrm{C}$ for 20 minutes. For fluorescently-labelled samples, Rhodamine B $(2 \times$ $10^{-4} \mathrm{~g} ; 10 \mathrm{mmol}$ ) was dissolved in $2 \mathrm{~mL}$ of deoxygenated water and the PSSS polyelectrolyte $(0.2 \mathrm{~g})$ was added to this and stirred for two hours. This was transferred to $10 \mathrm{~mL}$ of $\mathrm{Fe}^{3+} / \mathrm{Fe}^{2+}$ solution (2.70 g; $10 \mathrm{mmol}$, and $0.99 \mathrm{~g} ; 5 \mathrm{mmol}$ respectively), before addition of $10 \mathrm{~mL}$ of ammonia solution at $80^{\circ} \mathrm{C}$. The resulting black precipitates were washed with Millipore water $(5 \times 20 \mathrm{~mL})$ with the final two washings being used in TEM, DLS, FTIR, MRI and confocal measurements. The solid precipitate was analysed with XRD, TGA, HRTEM and SQUID measurements.

\subsection{MR imaging}

The tubes of different PSSS- $\mathrm{Fe}_{3} \mathrm{O}_{4}$ and $\mathrm{SPP}-\mathrm{Fe}_{3} \mathrm{O}_{4}$ concentrations were placed in a rack in the centre of the magnet. MR imaging was performed with a standard extremity flex coil on a clinical 3 T MRI scanner (Achieva, Philips Healthcare, Best, The Netherlands). $T_{2}$ was determined with a $2 \mathrm{D}$ multi-spin-echo sequence $\left(\mathrm{FOV}=120 \times 120 \mathrm{~mm}^{2}\right.$, matrix $=432 \times 432$, measured slice thickness $=3 \mathrm{~mm}$, echo train length $=5, \mathrm{TE}=$ $10 \mathrm{~ms}$, TR $=725 \mathrm{~ms}$, flip angle $=90^{\circ}$ ). The acquired imaging data was transferred to a computer running Matlab and analysed using an in-house Matlab tool to receive the relaxation time $T_{2}$ for each Fe concentration. Excel was used to plot the relaxation rate $R_{2}$ over the concentration and the relaxivity value was determined using linear regression. Iron concentrations of all MRI scanned serial dilutions of SPIONs were determined using Inductively Coupled Plasma Mass Spectrometry (ICP-MS). Briefly, samples were digested in $70 \%$ nitric acid overnight at room temperature, followed by dilution in deionized water. A standard curve was acquired with each sample set for iron concentration determination.

\subsection{Investigating the effect of nanoparticles on cell viability}

The effects of the nanoparticles on cell viability were determined in UKF-NB-3 neuroblastoma cells, primary human retinal pigment epithelial cells, and primary human foreskin fibroblast cells. UKF-NB-3 cells were cultivated in IMDM supplemented with $10 \%$ foetal calf serum (FCS), $100 \mathrm{IU} \mathrm{mL} \mathrm{m}^{-1}$ penicillin, and $100 \mathrm{mg} \mathrm{mL}{ }^{-1}$ streptomycin. Retinal pigment epithelial cells were cultured in DMEM supplemented with $20 \%$ FCS, $100 \mathrm{IU} \mathrm{mL} \mathrm{mL}^{-1}$ penicillin, and $100 \mathrm{mg} \mathrm{mL}^{-1}$ streptomycin. Fibroblasts were cultured in DMEM supplemented with $10 \%$ FCS, $100 \mathrm{IU} \mathrm{mL}^{-1}$ penicillin, and $100 \mathrm{mg} \mathrm{mL}^{-1}$ streptomycin. All cells were cultivated at $37{ }^{\circ} \mathrm{C}$ in humidified $5 \% \mathrm{CO}_{2}$ atmosphere as previously described..$^{\mathbf{7 0 , 7 1}}$ Cell viability upon the addition of nanoparticle preparations at different concentrations was determined by the 3-(4,5-dimethylthiazol-2-yl)-2,5diphenyltetrazolium bromide (MTT) dye reduction assay after $120 \mathrm{~h}$ of incubation as described previously. ${ }^{70,71}$

\subsection{Determination of cellular location of nanoparticles using fluorescence microscopy}

UKF-NB3 cells were seeded at $2 \times 10^{5}$ cells per well in a 24 well plate, containing a coverslip in each well, and grown at $37{ }^{\circ} \mathrm{C}$ for 48 hours. Rhodamine conjugated nanoparticles were diluted to $0.099 \mathrm{mg} \mathrm{L}^{-1}$ iron concentration in media, $1 \mathrm{~mL}$ added to appropriate wells and incubated for 3 hours before aspirating and fixing with methanol at $-20{ }^{\circ} \mathrm{C}$ for 5 minutes. Coverslips were mounted using mowiol and anti-fade and slides examined using a Leica confocal laser scanning (TCS $4 ; \times 63$ oil lens) microscope.

\section{Acknowledgements}

The authors gratefully acknowledge Prof. Ram Seshadri at UCSB for help, encouragement and for the use of SQUID facilities. These measurements were made possible through funding from the Royal Society of Chemistry Journal Grant for International Authors provided to SAC. SAC acknowledges funding by the EPSRC (EP/K029290/1) and the Royal Society (RG100301). SAC, ES and ERA gratefully acknowledge funding from the Leverhulme Trust (RPG-2015-134). RTMR is funded by The Centre of Excellence in Medical Engineering funded by the Wellcome Trust and EPSRC under Grant No. WT 088641/Z/09/Z. The authors acknowledge financial support from the Department of Health via the National Institute for Health Research (NIHR) comprehensive Biomedical Research Centre award to Guy's \& St Thomas' NHS Foundation Trust in partnership with King's College London and King's College Hospital NHS Foundation Trust.

\section{References}

1 Q. Zeng, I. Baker, J. A. Loudis, Y. Liao, P. Hoopes and J. B. Weaver, Appl. Phys. Lett., 2007, 90, 233112. 
2 Q. A. Pankhurst, J. Connolly, S. K. Jones and J. Dobson, J. Phys. D: Appl. Phys., 2009, 42, 224001.

3 C. Sun, J. S. Lee and M. Zhang, Adv. Drug Delivery Rev., 2008, 60, 1252-1265.

4 L. Ternent, D. A. Mayoh, M. R. Lees and G.-L. Davies, J. Mater. Chem. B, 2016, 4, 3065-3074.

5 H. B. Na, I. C. Song and T. Hyeon, Adv. Mater., 2009, 21, 2133-2148.

6 M. J. Williams and S. A. Corr, Frontiers of Nanoscience, Elsevier, 2013, pp. 29-63.

7 A.-H. Lu, E. L. Salabas and F. Schüth, Angew. Chem., Int. Ed., 2007, 46, 1222-1244.

8 Y.-X. J. Wang, Quant. Imag. Med. Surg., 2011, 1, 35-40.

9 D. Yoo, J.-H. Lee, T.-H. Shin and J. Cheon, Acc. Chem. Res., 2011, 44, 863-874.

10 L. H. Reddy, J. L. Arias, J. Nicolas and P. Couvreur, Chem. Rev., 2012, 112, 5818-5878.

11 J.-H. Park, G. von Maltzahn, M. J. Xu, V. Fogal, V. R. Kotamraju, E. Ruoslahti, S. N. Bhatia and M. J. Sailor, Proc. Natl. Acad. Sci. U. S. A., 2010, 107, 981-986.

12 Q. Song and Z. J. Zhang, J. Phys. Chem. B, 2006, 110, 1120511209.

13 R. Ladj, A. Bitar, M. Eissa, Y. Mugnier, R. Le Dantec, H. Fessi and A. Elaissari, J. Mater. Chem. B, 2013, 1, 1381-1396.

14 C. N. R. Rao, H. S. S. R. Matte, R. Voggu and A. Govindaraj, Dalton Trans., 2012, 41, 5089-5120.

15 G. R. Patzke, Y. Zhou, R. Kontic and F. Conrad, Angew. Chem., Int. Ed., 2011, 50, 826-859.

16 R. Massart, IEEE Trans. Magn., 1981, 1247-1248.

17 D. Kim, Y. Zhang, W. Voit, K. Rao and M. Muhammed, J. Magn. Magn. Mater., 2001, 225, 30-36.

18 S. Ge, X. Shi, K. Sun, C. Li, C. Uher, J. R. Baker Jr, M. M. B. Holl and B. G. Orr, J. Phys. Chem. C, 2009, 113, 13593-13599.

19 S. Sun and H. Zeng, J. Am. Chem. Soc., 2002, 124, 8204-8205.

20 Y. Tian, B. Yu, X. Li and K. Li, J. Mater. Chem., 2011, 21, 24762481.

21 A. G. Roca, M. P. Morales, K. O'Grady and C. J. Serna, Nanotechnology, 2006, 17, 2783.

22 S. Laurent, D. Forge, M. Port, A. Roch, C. Robic, L. V. Elst and R. N. Muller, Chem. Rev., 2008, 108, 2064-2110.

23 I. Bilecka and M. Niederberger, Nanoscale, 2010, 2, 13581374.

24 J. A. Gerbec, D. Magana, A. Washington and G. F. Strouse, J. Am. Chem. Soc., 2005, 127, 15791-15800.

25 T. E. Ashton, J. V. Laveda, D. A. MacLaren, P. J. Baker, A. Porch, M. O. Jones and S. A. Corr, J. Mater. Chem. A, 2014, 2, 6238-6245.

26 O. Pascu, E. Carenza, M. Gich, S. Estradé, F. Peiró, G. Herranz and A. Roig, J. Phys. Chem. C, 2012, 116, 1510815116.

27 C. Blanco-Andujar, D. Ortega, P. Southern, Q. A. Pankhurst and N. T. K. Thanh, Nanoscale, 2015, 7, 1768-1775.

28 R. M. Wong, D. A. Gilbert, K. Liu and A. Y. Louie, ACS Nano, 2012, 6, 3461-3467.

29 E. A. Osborne, T. M. Atkins, D. A. Gilbert, S. M. Kauzlarich, K. Liu and A. Y. Louie, Nanotechnology, 2012, 23, 215602.
30 I. Bilecka, I. Djerdj and M. Niederberger, Chem. Commun., 2008, 7, 886-888.

31 S. Komarneni, R. Roy and Q. H. Li, Mater. Res. Bull., 1992, 27, 1393-1405.

32 Q. Li and Y. Wei, Mater. Res. Bull., 1998, 33, 779-782.

33 X. Hu, J. C. Yu, J. Gong, Q. Li and G. Li, Adv. Mater., 2007, 19, 2324-2329.

34 X. Hu and J. C. Yu, Adv. Funct. Mater., 2008, 18, 880-887.

35 V. Sreeja and P. Joy, Mater. Res. Bull., 2007, 42, 1570-1576.

36 R. Y. Hong, T. T. Pan and H. Z. Li, J. Magn. Magn. Mater., 2006, 303, 60-68.

37 E. Carenza, V. Barcelò, A. Morancho, J. Montaner, A. Rosell and A. Roig, Acta Biomater., 2014, 10, 3775-3785.

38 J. Huang, H. Pen, Z. Xu and C. Yi, React. Funct. Polym., 2008, 68, 332-339.

39 F. Bensebaa, F. Zavaliche, P. L'Ecuyer, R. W. Cochrane and T. Veres, J. Colloid Interface Sci., 2004, 277, 104-110.

40 S. Komarneni, M. C. D’Arrigo, C. Leonelli, G. C. Pellacani and H. Katsuki, J. Am. Ceram. Soc., 1998, 81, 3041-3043.

41 S. A. Corr, Y. P. Rakovich and Y. K. Gun'ko, Nanoscale Res. Lett., 2008, 3, 87-104.

42 A. Guerrero-Martínez, J. Pérez-Juste and L. M. Liz-Marzán, Adv. Mater., 2010, 22, 1182-1195.

43 V. Salgueirino-Maceira and M. A. Correa-Duarte, Adv. Mater., 2007, 19, 4131-4144.

44 F. M. Kievit and M. Zhang, Acc. Chem. Res., 2011, 44, 853862.

45 M. Liong, J. Lu, M. Kovochich, T. Xia, S. G. Ruehm, A. E. Nel, F. Tamanoi and J. I. Zink, ACS Nano, 2008, 2, 889-896.

46 S. Liu, F. Lu, X. Jia, F. Cheng, L.-P. Jiang and J.-J. Zhu, CrystEngComm, 2011, 13, 2425-2429.

47 S. J. Byrne, S. A. Corr, Y. K. Gun'ko, J. M. Kelly, D. F. Brougham and S. Ghosh, Chem. Commun., 2004, 22, 2560-2561.

48 S. A. Corr, S. J. Byrne, R. Tekoriute, C. J. Meledandri, D. F. Brougham, M. Lynch, C. Kerskens, L. O'Dwyer and Y. K. Gun'ko, J. Am. Chem. Soc., 2008, 130, 4214-4215.

49 G.-L. Davies, S. A. Corr, C. J. Meledandri, L. Briode, D. F. Brougham and Y. K. Gun'ko, ChemPhysChem, 2011, 12, 772-776.

50 S. A. Corr, Nanoscience, 2013, 180-207.

51 R. Viswanatha and D. D. Sarma, Nanomater. Chem., 2007, 139-170.

52 O. N. Shebanova and P. Lazor, J. Raman Spectrosc., 2003, 34, 845-852.

53 L. Slavov, M. V. Abrashev, T. Merodiiska, C. Gelev, R. E. Vandenberghe, I. Markova-Deneva and I. Nedov, J. Magn. Magn. Mater., 2010, 322, 1904-1911.

54 D. Cunningham, R. E. Littleford, W. E. Smith, P. J. Lundahl, I. Khan, D. W. McComb, D. Graham and N. Laforest, Faraday Discuss., 2006, 132, 135-145.

55 P. Guardia, A. Labarta and X. Batlle, J. Phys. Chem. C, 2011, 115, 390-396.

56 M. Mikhaylova, D. K. Kim, N. Bobrysheva, M. Osmolowsky, V. Semenov, T. Tsakalakos and M. Muhammed, Langmuir, 2004, 20, 2472-2477. 
57 A.-L. Morel, S. Nikitenko, K. Gionnet, A. Wattiaux, J. Lai-KeeHim, C. Labrugere, B. Chevalier, G. Deleris, C. Petibois, A. Brisson and M. Simonoff, ACS Nano, 2008, 2, 847-856.

58 S. A. Corr, Y. K. Gun'ko, R. Tekoriute, C. J. Meledandri and D. F. Brougham, J. Phys. Chem. C, 2008, 112, 13324-13327.

59 S. Sun, H. Zeng, D. B. Robinson, S. Raoux, P. M. Rice, S. X. Wang and G. Li, J. Am. Chem. Soc., 2004, 126, 273-279.

60 Y. Wang, J. F. Wong, X. Teng, X. Z. Lin and H. Yang, Nano Lett., 2003, 3, 1555-1559.

61 Q. L. Vuong, J.-F. Berret, J. Fresnais, Y. Gossuin and O. Sandre, Adv. Healthcare Mater., 2012, 1, 502-512.

62 L. Sandiford, A. Phinikaridou, A. Protti, L. K. Meszaros, X. Cui, Y. Yan, G. Frodsham, P. A. Williamson, N. Gaddum, R. M. Botnar, P. J. Blower, M. A. Green and R. T. M. de Rosales, ACS Nano, 2013, 7, 500-512.

63 B. H. Kim, N. Lee, H. Kim, K. An, Y. I. Park, Y. Choi, K. Shin, Y. Lee, S. G. Kwon, H. B. Na, J.-G. Park, T.-Y. Ahn, Y.-W. Kim, W. K. Moon, S. H. Choi and T. Hyeon, J. Am. Chem. Soc., 2011, 133, 12624-12631.

64 J.-H. Park, G. von Maltzahn, L. Zhang, M. P. Schwartz, R. Ruoslahti, S. N. Bhatia and M. J. Sailor, Adv. Mater., 2008, 20, 1630-1635.
65 J. Qin, S. Laurent, Y. Jo, A. Roch, M. Mikhaylova, Z. Bhujwalla, R. Muller and M. Muhammed, Adv. Mater., 2007, 19, 1874-1878.

66 Z. Li, P. W. Yi, Q. Sun, H. Lei, H. Li Zhao, Z. H. Zhu, S. C. Smith, M. B. Lan and G. Q. M. Lu, Adv. Funct. Mater., 2012, 22, 2387-2393.

67 C. Sun, K. Du, C. Fang, N. Bhattarai, O. Veiseh, F. Kievit, Z. Stephen, D. Lee, R. G. Ellenbogen, B. Ratner and M. Zhang, ACS Nano, 2010, 4, 2402-2410.

68 D. Maity, G. Zoppellaro, V. Sedenkova, J. Tucek, K. Safarova, K. Polakova, K. Tomankova, C. Diwoky, R. Stollberger, L. Machala and R. Zboril, Chem. Commun., 2012, 48, 11398-11400.

69 U. S. Patil, S. Adireddy, A. Jaiswal, S. Mandava, B. R. Lee and D. B. Chrisey, Int. J. Mol. Sci., 2015, 26, 24417-24450.

70 M. Michaelis, C. Paulus, N. Löschmann, S. Dauth, E. Stange, H. Doerr, M. Nevels and J. Cinatl, Cell. Mol. Life Sci., 2011, 68, 1079-1090.

71 M. Michaelis, F. Rothweiler, B. Agha, S. Barth, Y. Voges, N. Löschmann, A. von Deimling, R. Breitling, H. W. Doerr, F. Rödel, D. Speidel and J. Cinatl Jr, Cell Death Dis., 2012, 3, e294. 